\title{
Reporting a Success Story in the Context of Public Sector: Factors That Matters
}

\author{
Haitham Jahrami Ph.D. (Corresponding author) \\ Psychiatric Hospital, Ministry of Health \\ PO Box 5128, Manama, Bahrain \\ Tel: +973 17286334 Fax: +973 17270637 E-mail: hjahrami@health.gov.bh \\ Mohammed Buheji Ph.D. \\ Bahrain Centre of Excellence, Court of Prime Minister \\ P.O.Box 1000, Manama, Bahrain \\ Tel: +973 17212220 Fax +973 17213322 E-mail: buhejim@gmail.com
}

Received: August 07, 2012 Accepted: September 17, 2012 DOI: 10.5296/jpag.v2i3.2470

\begin{abstract}
Given the unclear nature of defining any business success stories in the literature, the present article examines the use of factor analytic techniques on the evaluations of 32 success stories presented by different organisations in the 1st National Forum for success stories in Bahrain held in October, 2011. Standard evaluation forms were designed by an independent expert's panel incorporating 15 items. Each success story was evaluated by 6-8 public administration consultants. Data were subjected to EFA techniques using Maximum Likelihood Extraction with Promax Rotation, 239 evaluation forms were examined. Three factors were retained by the analysis (a) clarity, (b) competitiveness and (c) sustainability. Recommendations are proffered for future practice as regards of analytic and evaluative decisions of success stories and reporting it in an empirical language. Numerous lectures, guidelines and descriptions exist to aid writing a success story; nonetheless, these remain to be an 'opinion' or a 'reflection' of their writer. The findings of the analysis in this research reveal that three factors are considered essential for an effectively reported success story: (a) clarity, (b) competitiveness and (c) sustainability.
\end{abstract}

Keywords: Success Story, Factor Analysis, Business Excellence, Bahrain, Public Administration 


\section{Introduction}

We have all heard the term business excellence success story, we initially thought it is self-explanatory but after 10 minutes search on Google, what are we really talking about? It seemed that success stories cone in all sizes, shapes and colours but they all share the eager to communicate, 'look at me, I am smart, competitive, innovating, learning'. One more time what is a success story? A simple definition for a 'success story' would be something like a narrative or an anecdote highlighting the achievements, challenges and progress of a programme or a project or an activity. Effectively reported success story document and communicate improvement for a defined timeframe and demonstrate the value adding facets of the project and its activities. Sharing success stories are a very powerful tool for sharing good practices and the results achieved. One practical point about sharing success stories is attracting and building new partners for collaboration and integration, reflecting the visionary, "can-do" and energising spirit done towards human values (Tee and Tan, 2006). Government organizations specifically are more in need for such success stories that would give clear examples how such organizations can transform itself in the current unstable global economy (Murray, 2008). The success case story is thought to help in wide spreading the recognition of the importance of intelligence and knowledge sharing within the government entities (Seba and Rowley, 2010). Reporting 'success stories' is a very common approach in business excellence frameworks; these stories serves as living examples of why business excellence does or indeed sometimes does not work (Unwin, 2011).

It is therefore very clear the importance of these success stories for Business Excellence, for example; an online shared lecture by Dr Keller entitled 'Writing Effective Success Stories' clearly explains the importance of success stories as a communication tool, because they:

a) provide a framework for understanding, remembering, and acting on information

b) shares best practices

c) communicate achievements and gives accountability to accomplishments.

Nevertheless the information presented in the literature is merely personal opinions and reflections about the topic and has no grounded scientific basis for it (Keller, 2011). An electronic search of two leading databases Emerald and ProQuest using all possible combinations of the following keywords: "success story, success stories, business excellence, quality management, excellence framework" revealed very few hits with no research article that is directly relevant to the current topic. This keyword search exercise clearly highlights the shortage of research about success stories in business excellence. The authors must explicitly acknowledge that there has been research reported in the literature that describes a 'success story' a result of implementing a business excellence framework; this does not however research the success story reporting approach. 


\section{Study Background}

The Bahrain Centre of Excellence (BCE) was established in June 2008, as an initiative from Prime Minister Court in Kingdom of Bahrain that targeted to bring up excellence and sustainable practices and values in the culture of all Bahraini Organizations, but with particular focus on public sector organizations through a unique competency building program that use knowledge network, learning and innovation as the basis for its programs. The Centre bases its activity on the concept of social networking and implementation techniques that are measureable towards better organisational sustainability. There are more than 50 organisations mainly governmental and semi-governmental. BCE targets to extent activities to private and non-governmental organizations starting from year 2012. BCE have a non-compulsory annual evaluation of the participating organizations success stories based on values that create better culture.

In September 2011; as part of knowledge sharing; the BCE invited 50 Bahraini public organizations including all Ministries and Authorities to submit a 15 minutes PowerPoint presentation and abstract to share a success story in the $1^{\text {st }}$ Success Stories Forum. The BCE programme delivered a half-day workshop on how to select and report a success story for all senior officials and local consultants in the Bahraini public organizations. The BCE also issued a guideline on the best practices for writing a success story which was sent to all organization's through a CD and was also published on the BCE official website.

The forum lasted for two days $3^{\text {rd }}$ and $4^{\text {th }}$ October, 2011 and together 32 success stories were presented by 32 different organizations. Six to eight BCE consultants were assigned as a panel for evaluating the presentations for content and style using a 15 items close ended rating scale. Each panel was chaired by a senior government official from the BCE top leadership and co-chaired by another BCE consultant along with other members whom are all trained consultants in the BCE programme. These members represent expertise in technical fields, professionals, academics and public administration. It is also worthy to mention here that the form which was used for evaluation was designed by an independent scientific committee including the national consultants and was revised, piloted and edited several times before approval.

\section{Methodology}

Following the closing ceremony of the forum this research idea was sparked to reveal empirically the factors that would be important in defining a success story using a retrospective data collected during the forum. Due to the exploratory nature of this project no formal hypotheses were formulated. An ethical approval was sought from the Bahrain Centre of Excellence authorities before using these data for research purposes.

All of the evaluation forms $(n=239)$ for all organizations were subjected to exploratory data analysis to answer the principal research question of the factors or elements that would define a success story. 


\section{Macrothink}

Factor analysis was invented nearly 100 years ago by a psychologist Charles Spearman who hypothesised that the enormous variety of tests of mental ability - measures of mathematical skills, vocabulary, other verbal skills, artistic skills, logical reasoning ability, etc. - could all be explained by one underlying hidden or latent variable called factor, which in Spearman's case was General Intelligence (Tacq, 1997). Factor analysis is therefore concerned with the reduction of a set of observable variables in terms of small number of latent variables or so-called factors with a minimum loss of information. Factor analysis is therefore concerned with the reduction of a set of observed variables into small number of latent/hidden/unobserved variables or what so-called factors with a minimum loss of data.

A factor analysis of the 15 rating items in the forms was conducted using the 239 cases. In general there are various conditions about what ratio of cases (participants) to variables (items), ranging from 2:1 to 10:1. Larger samples are always needed to obtain a stable solution, but there are no absolute criteria for deciding what is large. Estimates range from 150 (as a minimum) to 500 when there are 40+ variables (Cliff, 1983). The ratio of cases to variables depends to some extent on the specific aims of the analysis, the properties of the data, the number of factors to be extracted and the size of the correlations (Wolins, 1982).

\section{Results}

Before running the factor analytic procedure the Kaiser-Meyer-Olkin (KMO) Measure of Sampling Adequacy (MSA) and Bartlett's Test of Sphericity were studied to statistically determine suitability for conducting a factor analytic procedure. The MSA index "ranges from 0 to 1 , reaching 1 when each variable is perfectly predicted without error by the other variables" (Hair et. al., 1998, pp. 90). As shown in Table 1 the MSA measured 0.97 indicating that a factor analysis would be highly useful with the data. Furthermore, the Bartlett's Test of Sphericity for the presence of statistical correlations, revealed a significance level of 0.000 indicating that there were a high probability of significant relationships among the variables (Norusis, 1994).

Taken together the results of the KMO measure of sampling adequacy and Bartlett's test of sphericity provided a good basis for qualifying for a factor analysis. Thus, after an assurance that the factor analysis was appropriate, an exploratory factor analysis was carried out on the using maximum likelihood extraction. The maximum likelihood extraction method was selected because of its known sensitivity in factor extraction as it produces parameter estimates that are most likely to have produced the observed correlation matrix. The factors were rotated using the oblique type of rotation (promax rotation) to allow the factors to be correlated with each other's. The decision to employ only oblique rotation results rests on its advantages thereof considering the research objectives. 
Table $1 \mathrm{KMO}$ and Bartlett's Test

\begin{tabular}{|l|r|}
\hline Kaiser-Meyer-Olkin Measure of Sampling Adequacy. & .966 \\
Bartlett's Test of Sphericity $\quad$ Approx. Chi-Square & 3441.395 \\
& df \\
Sig. & .000 \\
\hline
\end{tabular}

Cattell's scree test was administered to determine the number of factors to be extracted. The scree plot demonstrated that a solution of three factors would be the best to retain a conceptually clear and interpretable factor solution that would explain $73 \%$ of the total variance.

Table 2 Structure Matrix

\begin{tabular}{|l|r|r|r|}
\hline & \multicolumn{2}{|c|}{ Factor } \\
\cline { 2 - 4 } & \multicolumn{1}{|c|}{1} & \multicolumn{1}{|c|}{3} \\
\hline Explain and identify the scope of the success story & .783 & .944 & .740 \\
Objectives of the success story & .762 & .912 & .685 \\
Measurements of performance & .738 & .772 & .651 \\
The source of the story/ opportunities for improvement & .806 & .836 & .771 \\
Learning opportunities and sources & .813 & .777 & .751 \\
Competitive (better quality - the best cost - the best delivery) & .713 & .664 & .919 \\
Best practices supporting the management of resources & .738 & .703 & .817 \\
How to identify partnerships and integration, commensurate with the importance & .730 & .659 & .577 \\
The application of the concept of knowledge management & .831 & .690 & .760 \\
Approach used in the success story & .885 & .818 & .716 \\
Change Management & .834 & .726 & .743 \\
The role of leadership and leadership teams & .795 & .695 & .639 \\
How to deal with the challenges and success & .810 & .733 & .762 \\
Mechanism to promote sustainability & .859 & .693 & .735 \\
Green circle/the requirements of the citizen & .733 & .700 & .778 \\
\hline
\end{tabular}

Extraction Method: Maximum Likelihood.

Rotation Method: Promax with Kaiser Normalization.

The first factor contained four items, eigenvalue of 10.4 and explained $64 \%$ of the total variance. Items in this factor were about the nature of the success story, the goals of the success stories, the KPIs used in the success story, the origin and sources of the success story. Thus, this factor was labelled as the 'Clarity' of the success story.

The second factor contained three items, eigenvalue of 0.7 and explained $4.5 \%$ of the total variance. Items in this factor were about the quality, cost, delivery components, the best practices in the management of resources and the needs and wants of the end users. Thus, this factor was labelled as the 'Competiveness' of the success story. 
The third factor contained eight items, eigenvalue of 0.6 and explained $4 \%$ of the total variance. Items in this factor were about partnership with others, knowledge management, approach to best practices, change management, opportunities for learning, role of leadership, dealing with challenges, mechanisms for sustainability. Thus, this factor was labelled as the 'Suitability' of the success story.

The structure matrix is simply the factor loading matrix as in orthogonal rotation, representing the variance in a measured variable explained by a factor on both a unique and common contributions basis.

The entire details of the structure matrix using the extraction method: Maximum Likelihood and rotation method: Promax with Kaiser Normalization are presented in Table 2.

\section{Discussion and Conclusion}

Several descriptive literature exists that would describe what is a success story, the significance of reporting a success story, the need of reporting success stories and so on. The literature would generally suggest that a success story can be written about an entire project or part of a project that is particularly worth worthy and significant. It may be about an innovation, disaster response or outstanding effort. The project may be complete or ongoing. The literature however has very little empirical information about what makes a "good" success story? Answer to this question would be drawn from personal experience or previous theoretical knowledge and indeed common sense. The best available literature would tell us that a good success story includes: a success, credible information, backed up with evaluation and evidence, clearly communicated without technical jargons and acronyms; with simple familiar words over stuffy, academic and unfamiliar words. These answers are intuitive but at their best descriptive and do not promote to the level of scientific evidence based practices. This work shades a line to the type of organisational image portfolio mapping and way of presenting it periodically to concerned parties. This small scale research was initiated to fill a gap in the literature and open new path for researchers for defining what are the dimensions to be considered as important when reporting a success story.

Most of the times, the literature confuses us about how long 'success stories' should go to attract and deliver the right message to more viewers and customers. The findings of this research study have practical implications to the point above in two ways, first; to ensure that the main ingredients are included so the content is clear. Second, the amount of details to be given and thus governing the length of the case study.

This study had several limitations: first, the retrospective research design. Studies done this way, however, have several problems. The largest issue may be that correlation does not imply causation. Still, retrospective studies are cheaper and quicker than prospective studies, studies are often retrospective. Second, the reliance on evaluations from different 'assessors' can be an issue. However, the presence of a standard evaluation form helped standardise the manner in which evaluations were made. Third, the research design was limited to one country using single evaluation form; thus therefore, the results cannot yet be regarded as 
generalisable to any population of clinicians beyond those in the study.

Success stories will continue to be a hot area for authors, especially those who are interested in Business Excellence frameworks. This study clearly indicates that while the topic is growing researchers did not seem to pay enough attention to it. Numerous lectures, guidelines and descriptions exist to aid writing a success story; nonetheless, these remain to be an 'opinion' or a 'reflection' of their writer. The findings of the analysis in this research reveal that three factors are considered essential for an effectively reported success story: (a) clarity, (b) competitiveness and (c) sustainability. While one might argue that these dimensions has been discussed by previous anecdotal literature, the authors will argue back the ability to demonstrate their importance using scientific research methodologies will help toward an evidence-based 'success stories' reporting. Future research are encouraged to go with this line to fill an important theoretical and practical gap in our literature and practice. The major implication of this study is therefore to motivate researchers and practitioners to continuously reflect on the concept of a 'success story'. Simply, a story to be defined as a 'success' a scientifically predefined parameters should be fulfilled this is especially true for developing countries where instability exists.

\section{Acknowledgement}

The authors would like to thank Shaikh Dr Mohammed Bin Abdulla Al-Khalifa for his support and assistance with this project and for his appreciation of the benefits to be gained from such a scientific research.

\section{References}

Chan, D. (2000) The story of Singapore airlines and the Singapore girl, Journal of Management Development, 19(6): 456-472.

Cliff, N. (1983) Some cautions concerning the application of causal modelling methods, Multivariate Behavioural Research, 18, 115-126

Keeler, K. (2011) Writing effective success stories [extension.missouri.edu/fnep/effectivestories.ppt] Accessed December 19, 2011

Murray, A. (2008) Government as a knowledge enterprise, KM World; Apr; 17(4): 22.

Norusis, N. M. (1994) SPSS/PC+ Studentware Plus ${ }^{\mathrm{TM}}$ for Business, USA, Chicago: IL, SPSS Publications.

Seba,I \& Rowley,J (2010) Knowledge management in UK police forces, Journal of Knowledge Management, 14(4): 611-626.

Tacq, J. (1997) Multivariate analysis techniques, Sage Publications, Thousand Oaks: CA.

Tee Ng, P. \& Tan, C. (2006) From school to economy: innovation and enterprise in Singapore he innovation, The Public Sector Innovation Journal, 11(3), article 5, 1-12. 


\section{Macrothink}

Unwin, S. (2011) The explorer's guide to business excellence

[http://www.accesstoexcellence.co.uk/html/explorer_s_guide.html] Accessed December 19, 2011

Wolins, L. (1982) Research mistakes in the social and behavioural sciences, Iowa State University Press, Ames.

\section{Copyright Disclaimer}

Copyright reserved by the author(s).

This article is an open-access article distributed under the terms and conditions of the Creative Commons Attribution license (http://creativecommons.org/licenses/by/3.0/). 